\title{
Mild and severe muscular dystrophy associated with deletions in Xp21 of the human X chromosome
}

\author{
K E DAVIES*, T J SMITH*, S BUNDEY†, A P READ , T FLINT*, \\ M BELL*, AND A SPEER§
}

From ${ }^{*}$ the Nuffield Department of Clinical Medicine, University of Oxford, John Radcliffe Hospital, Oxford OX3 9DU; †Infant Development Unit, Birmingham Maternity Hospital, Edgbaston, Birmingham B15 2TG; $\ddagger$ the Department of Medical Genetics, University of Manchester, St Mary’s Hospital, Hathersage Road, Manchester M13 OJH; and \$the Department of Cell Differentiation, Institute of Molecular Biology, Academy of Sciences of DDR, Robert Rossle Strasse 10, 115 Berlin, GDR.

SUMmARY We have analysed over 300 patients suffering from Duchenne or Becker muscular dystrophy (DMD or BMD). Deletions have been characterised which encompass either the pERT87 (DXS164) locus only, the XJ1-1 (DXS206) and HIP25 loci only, or all three loci. These loci have been shown to lie within the DMD region covering several hundred kilobases $(\mathrm{kb})$ of DNA. One mildly affected BMD patient possesses a deletion of at least $110 \mathrm{~kb}$ including exons of the DMD gene. Other patients with similar exon deletions, or smaller deletions, show the more severe phenotype typical of DMD. We conclude from these studies that the severity of the clinical phenotype cannot be explained on the basis of the size of the deletion. We discuss this in the context of candidate gene sequences.

Duchenne muscular dystrophy (DMD) is an $\mathrm{X}$ linked recessive condition affecting 1 in 3000 males. ${ }^{1}$ Affected boys are normally wheelchair bound by the age of 11 or 12 years and die in their late teens. Patients suffering from the clinically milder form of disease, Becker muscular dystrophy (BMD), go into a wheelchair much later and may have a normal life span. These disease loci were thought to lie within $\mathrm{Xp} 21$ on the human $\mathrm{X}$ chromosome from cytogenetic observations of females suffering from the disease with balanced $\mathrm{X}$; autosome translocations (for review see Elejalde and Elejalde ${ }^{2}$ ). The breakpoints of these translocations lie within the Xp21 band but have been shown to be heterogeneous. ${ }^{3}$ Studies using DNA markers confirmed the localisation of $D M D$ to $\mathrm{Xp} 21$ and placed $B M D$ in the same region. ${ }^{4-6}$

Carrier detection and prenatal diagnosis of these disorders has been greatly improved by the use of restriction fragment length polymorphisms (RFLPs) bridging the mutations. ${ }^{7}$ More recently, DNA markers have been isolated which lie within, or very close to, the DMD locus itself. pERT87 was isolated by Kunkel et al $^{8}$ and shown to be deleted in $7 \%$ of

Received for publication 6 April 1987 Accepted for publication 7 April 1987. affected males. ${ }^{9}$ Chromosome walking from this sequence has led to the identification of expressed regions of the DMD gene. ${ }^{10}$ The corresponding mRNA is $16 \mathrm{~kb}$, showing that this locus must encode a large protein. The middle filament protein Nebulin, which is $550 \mathrm{kd}$, has been suggested as a possible candidate protein not only because of its size but also because of its absence in DMD patients. ${ }^{11}$

Ray et $a^{12}$ cloned the translocation breakpoint in the female with the $X ; 21$ translocation to isolate a DNA marker for the disease, $\mathrm{XJ} 1 \cdot 1$. This has been shown to lie approximately $200 \mathrm{~kb}$ centromeric from pERT87 in pulsed field gel electrophoresis studies. ${ }^{13-15}$ This sequence is also deleted in some DMD patients.

We have isolated a sequence, HIP25, by subtractive hybridisation, which is deleted in $7 \%$ of DMD patients. ${ }^{16}$ In the study presented here we have analysed our patients with pERT87, XJ1・1, and HIP25 together with other markers derived from chromosome walks in the region. These DNA markers cover approximately $1000 \mathrm{~kb}$ of the DMD locus.

\section{Methods}

DNA EXTRACTION

DNA was extracted according to the method of 
Kunkel et $a l^{17}$ and digested with the restriction enzyme PstI according to the manufacturer's instructions.

\section{SOUTHERN BLOT ANALYSIS}

Gels were run in $0.8 \%$ agarose (BRL) and blotted onto Hybond (Amersham) according to the method of Southern. ${ }^{18}$ The blots were hybridised as described previously. ${ }^{4}$

\section{PROBES}

Probes pERT87-1, 8, 15, 30, 41, and JBir were kind gifts from Dr Kunkel (Boston). These are described in detail in Monaco et al. ${ }^{19} \mathrm{XJ} 1 \cdot 1$ was a kind gift from Dr Worton and corresponds to the breakpoint in the $\mathrm{X} ; 21$ translocation female. ${ }^{12}$ HIP25 was isolated in our own laboratory by Smith et al. ${ }^{16}$ Further information on these probes and others given in the table can be found in Human Gene Mapping $8^{20}$ and references $8,12,16$, and 21 .

The DNA segments pERT87 and XJ have been assigned the names DXS164 and DXS206 respectively.

\section{Results}

We have screened over 300 patients suffering from DMD and BMD with probes from the Xp21 region. The pERT87 locus has been extended by chromosome walking and the subclones that cover this region (pERT87-1, 8, 15, 30, 41) have been used independently. JBir is a deletion junction clone isolated from a DMD patient by Monaco et al. ${ }^{19} \mathrm{XJ} 1 \cdot 1$ and HIP25 loci are within $20 \mathrm{~kb}$ of one another and have so far revealed the same pattern with respect to deletions in patients. Approximately $10 \%$ of patients showed deletions with these probes.

A typical blot is shown in fig 1. A series of DMD patients are shown hybridised to the probes pERT87-41 and JBir. Most of these patients are

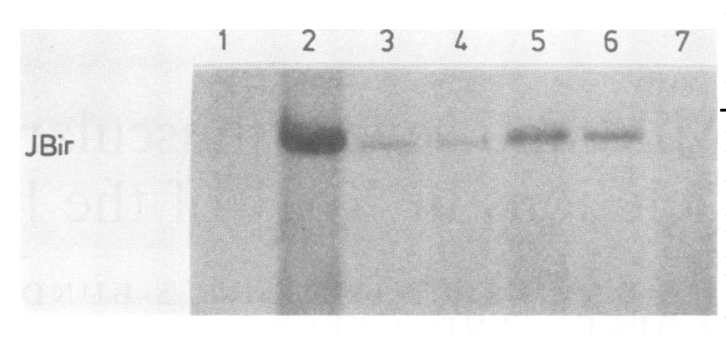

FIG 1 Southern blot analysis of DMD patients; $5 \mu \mathrm{g}$ DNA was digested with PstI. The patient samples in the tracks are as follows: (1) 324; (2) 339; (3) 1338; (4) 1339; (5) 1406; (6) 1426; (7) 1431.

positive for the latter and negative for the former indicating deletion endpoints between these two markers. A summary of the deletions that we characterised across the DMD region is given in the $\frac{}{\varnothing}$ table. The DMD boys have deletions ranging in size $\vec{F}$ from 10 to $50 \mathrm{~kb}$, as in patient 1422 , to relatively윽 large ones, as in patient 1426 (at least $300 \mathrm{~kb}$ ). None of these boys is mentally retarded and they all show a similar clinical course. There are no significant differences between sporadic and familial cases.

The two BMD cases shown at the bottom of the table were of particular interest because they have deletions and yet are mildly affected. The pedigree corresponding to patient 324 is given in fig 2 . Patient₹ 324 is subject III.1. He showed, no neurologicalo

TABLE Summary of DNA probe deletions in patients.

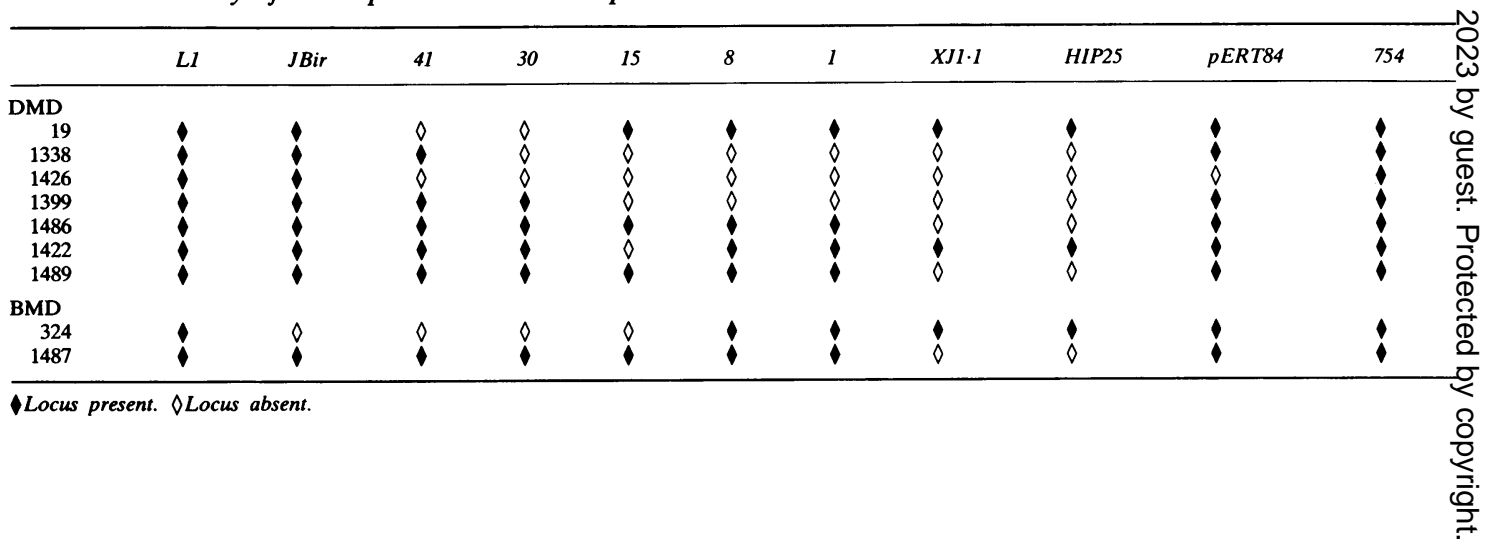




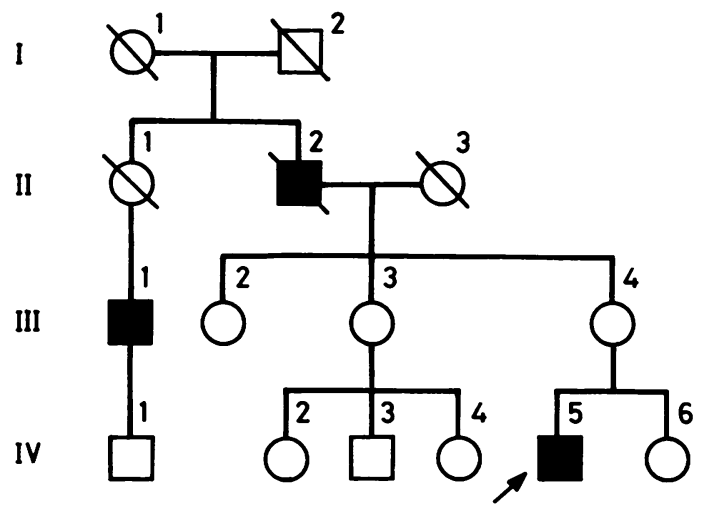

FIG 2 Pedigree of patient 324 (III.1)

symptoms until his thirties, and photographs taken before then do not reveal any signs of pseudohypertrophy of the calves. His first neuromuscular symptom came when he fell while running for a bus at the age of 35 years and three years later he saw a neurologist and was told that he had X linked muscular dystrophy. Now at the age of 61 he can walk with a stick, but only for short distances. He can manage to crawl upstairs and he is still driving a car. Examination reveals very little weakness of the arms, but severe weakness of hip flexors and extensors, and severe weakness of the quadriceps femoris. His hip abductors and adductors are only mildly affected.

Subject IV.5 complained about difficulty in rising from a squatting position and noticed that one leg occasionally gave way on walking. These symptoms were minor and he only attended a neurologist because of his family history. On examination he was found to have large quadriceps muscles and had some weakness of the pelvic girdle when rising from the floor, but no other abnormal signs. An EMG showed polyphasic potentials characteristic of a muscular dystrophy and his creatine kinase level was $3318 \mathrm{IU} / \mathrm{l}$ which confirmed the clinical diagnosis of BMD. He had no deletion of Kell, Cellano, or KPB blood groups.

Subject II.2 died at the age of 52 years after a cerebral haemorrhage. At this time he was having difficulty in walking and needed a stick.

Subject III.1 (patient 324 in the table) and IV.5 had identical deletions in our DNA analysis. The absence of JBir and pERT87-41 is shown in track 1 of fig 1 . The proximal breakpoint of the deletion lies between pERT87-8 and pERT87-15, as shown in fig 3 , where patient 324 shows a positive signal for the former but a negative signal for the latter. This gives a deletion in these patients of at least $110 \mathrm{~kb}$.

The second BMD case shown in the table (1487) showed a rather different clinical course. His disease progressed exactly as would be expected for DMD and he was wheelchair bound at the age of 11 years. However, further muscle weakness did not follow and he is currently running his own business from his

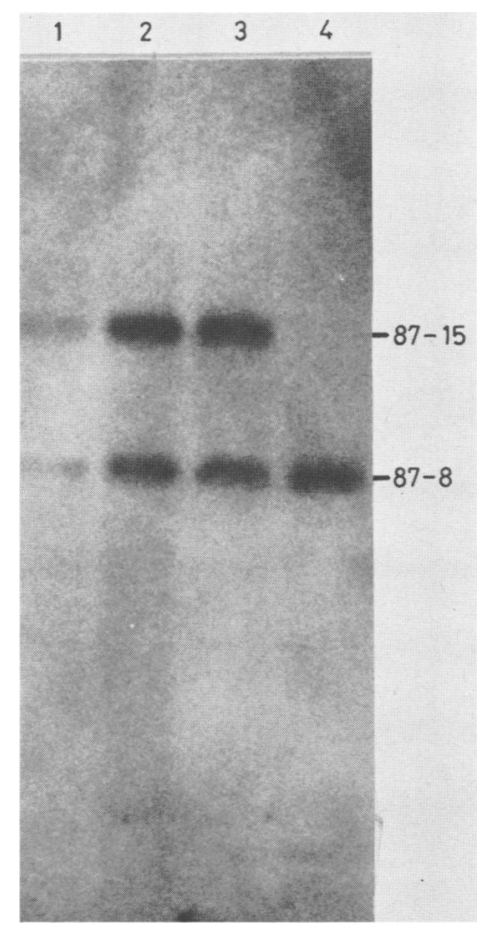

FIG 3 Southern blot analysis of the proximal breakpoint of the deletion in patient 324 (track 4). Track 1, normal male; tracks 2 and 3, DMD males. The samples were digested with PstI.
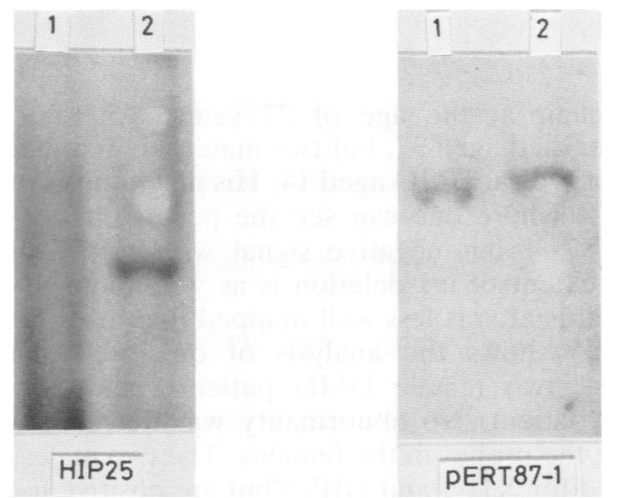

FIG 4 Southern blot analysis of patient 1487 (track 1) and non-deleted DMD male (track 2). DNA was digested with PstI. 

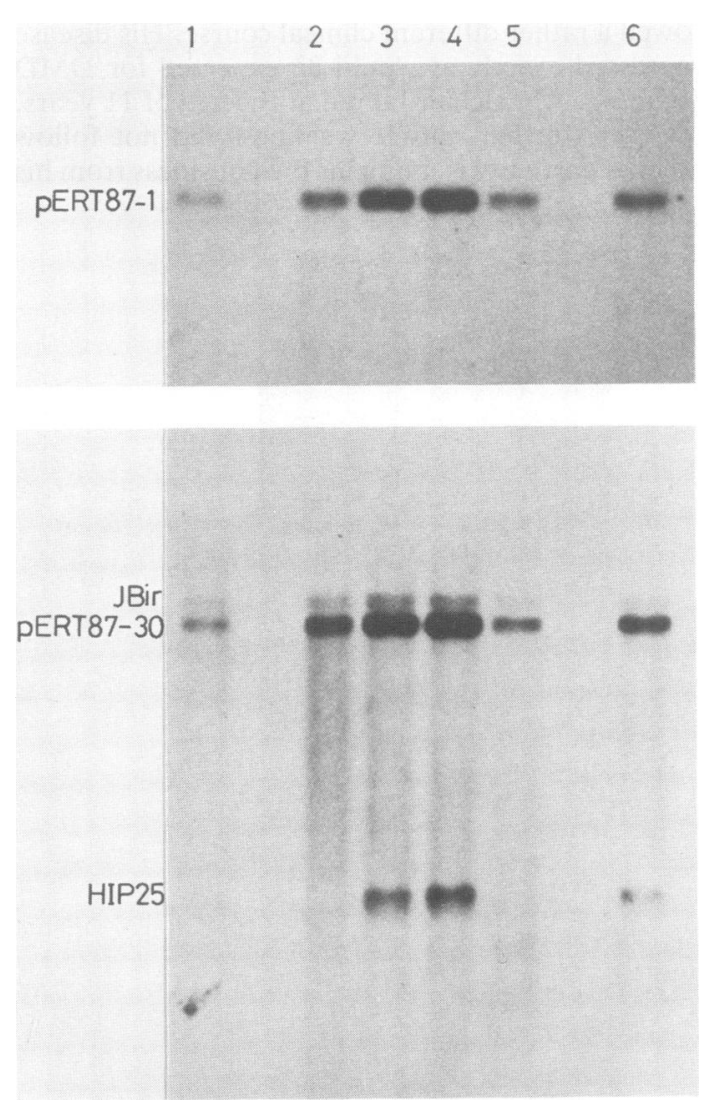

FIG 5 Southern blot analysis of DMD and BMD patients; $5 \mu \mathrm{g}$ DNA was digested with PstI. Tracks 1 and 6, normal males; track 2, DMD patient 1517; track 3, female patient 1518; track 4, female patient 1519; track 5, BMD patient 1516.

wheelchair at the age of 27 years. An affected brother died aged 37, but two maternal great uncles died of typical DMD aged 14. His deletion is shown in fig 4 where one can see the positive signal for pERT87-1 but negative signal with HIP25. The exact extent of his deletion is as yet unknown because this area is less well mapped than pERT87.

Fig 5 shows the analysis of one male DMD patient, two female DMD patients, and a male BMD patient. No abnormality was detected with any of the probes in the females. The two males are deleted for XJ1.1 and HIP25 but are positive for all the pERT87 probes. The relationship of these two deletions with respect to one another remains to be determined.

\section{Discussion}

These data show that the extent of deletions found $\overrightarrow{\vec{\rho}}$ in patients is not related in a simple manner to theo severity of the phenotype. Small deletions can lead흐 to both severe DMD and mild BMD. This has been⿳亠口冋. noted by others. ${ }^{22-25}$ This suggests that it is possible $\bar{Q}$ to remove parts of the gene such that if the processing of the transcript remains in a phase for trans- - s lation a functional protein can be produced. This $\vec{\circ}$ protein of course will not be as efficient in its action $\overrightarrow{\mid}$ as the normal gene product. In cases of severe DMD the deletion must severely affect the integrity of the protein product and in some cases it might coms pletely inhibit the production of protein. The exact mechanisms of these processes must await the deter- $-\overrightarrow{0}$ mination of the breakpoints and the exons of the gene involved in the deletions.

One of the striking results reported here is the clinical presentation of patient 324 who possesses deletion of at least $110 \mathrm{~kb}$ and yet is very mildly affected. From the knowledge of the exons presene in this region of the gene, this patient must be miss $\overrightarrow{0}$ ing at least four coding regions of the protein. Thus he must be able to cope with a truncated protein of have some way of compensating very efficiently for the lack of production of the DMD gene product We are currently using cDNA clones to map and sequence his deletion endpoints.

The identification of mild patients who may b® producing smaller proteins than normal males ma $\overrightarrow{5}$ allow us to characterise the smallest possible func $\exists$ tional unit of this unusual protein. In this way we hope to be able to gain some insights into the disease. pathology and possible therapies for this disordes in the future.

We would like to thank Drs Kurnath, Schieber Spiegler, Sommer, Emery, Dubowitz, Bobrow, an Fischbeck for patient blood samples. We also thank Dr Adrian Williams for information on IV.5 frons the family in fig 2 . We are grateful to the Medica Research Council, the Muscular Dystrophy Associo ation of America, and the Muscular Dystroph Group of Great Britain and Northern Ireland for financial support. AS would like to thank the Wellcome Trust for financial support. TJS is recipient of a SERC Instant Award.

\section{References}

1 Gardner-Medwin D. Clinical features of classification of the muscular dystrophies. Br Med Bull 1980;36:109-15.

2 Elejalde BR, Elejalde MM. Phenotypic manifestations of $X 6$ autosome translocations. In: Sandberg AA, ed. Cytogenetics oळ the $X$ chromosome. New York: Alan R Liss, 1983:225-44@

3 Boyd Y, Buckle VJ. Cytogenetic heterogeneity of translocß tions associated with Duchenne muscular dystrophy. Clin Genes 1986;29:108-15. 
${ }^{4}$ Murray JM, Davies KE, Harper PS, et al. Linkage relationship of a cloned DNA sequence on the short arm of the X chromosome to Duchenne muscular dystrophy. Nature 1982;300:69-71.

5 Davies KE, Pearson PL, Harper PS, et al. Linkage analysis of the two cloned DNA sequences flanking the Duchenne muscular dystrophy locus on the short arm of the human X chromosome. Nucleic Acids Res 1983;11:2303-12.

6 Aldridge J, Kunkel L, Bruns G, et al. A strategy for construction of highly polymorphic DNA haplotypes in specific human chromosomal regions: application to linkage analysis of $\mathrm{X}$ chromosome specific diseases such as Duchenne muscular dystrophy. Ital J Neurol Sci 1984;3:39-46.

${ }^{7}$ Bakker E, Hofker MH, Goorl N, et al. Prenatal diagnosis and carrier detection of Duchenne muscular dystrophy with closely linked RFLPs. Lancet 1985;i:655-8.

${ }^{8}$ Kunkel LM, Monaco AP, Middlesworth W, et al. Specific cloning of DNA fragments absent from the DNA of a male patient with an X chromosome deletion. Proc Natl Acad Sci USA 1985;82:4778-82.

9 Kunkel LM, Hejtmancik JF, Caskey CT, et al. Analysis of deletions in DNA from patients with Becker and Duchenne muscular dystrophy. Nature 1986;322:73-7.

10 Monaco AP, Neve RL, Colletti-Feneer C, et al. Isolation of candidate cDNAs for portions of the Duchenne muscular dystrophy gene. Nature 1986;323:646-50.

11 Wood DS, Zeviani M, Prelle A, et al. Is nebulin the defective gene product in Duchenne muscular dystrophy. $N$ Engl J Med 1987:316:107-8

12 Ray PN, Belfall B, Duff C, et al. Cloning of the breakpoint of an $\mathrm{X} ; 21$ translocation associated with Duchenne muscular dystrophy. Nature 1985;318:672-5.

13 Kenwrick S, Patterson MN, Speer A, et al. Molecular analysis of the Duchenne muscular dystrophy region using pulsed-field gel electrophoresis. Cell 1987;48:351-7.

${ }^{14}$ Burmeister M, Lehrach H. Long range restriction map around the Duchenne muscular dystrophy gene using pulsed-field gel electrophoresis. Nature 1986;324:582-5. 1s van Ommen GJB, Verkerk JMH, Hofker MH, et al. A physical map of 4 million bp around the Duchenne muscular dystrophy gene on the human X chromosome. Cell 1986;47:499-504.

16 Smith TJ, Wilson L, Kenwrick SJ, et al. Isolation of a conserved sequence deleted in some DMD patients. Nucleic Acids Res 1987;15:2167-74.

17 Kunkel LM, Smith KD, Boyer SH, et al. Analysis of human Y chromosome specific reiterated DNA in chromosome variants. Proc Natl Acad Sci USA 1977;74:1245-9.

${ }^{18}$ Southern EM. Detection of specific sequences among DNA fragments separated by gel electrophoresis. J Mol Biol 1975;98: 503-17.

${ }_{19}$ Monaco AP, Bertelson CJ, Colletti-Feneer C, Kunkel LM. Localisation and cloning of deletion breakpoints in Xp21 involved in muscular dystrophy. Hum Genet 1987;75:221-7.

20) Goodfellow PN, Davies KE, Ropers HH, Report of the committee on the genetic constitution of the $\mathrm{X}$ and $\mathrm{Y}$ chromosomes. Cytogenet Cell Genet 1985;40:296-352.

21 Paulsen K, Forrest S, Scherer G, et al. Regional localisation of X chromosome short arm probes. Hum Genet 1986;74:155-9.

22 Monaco AP, Bertelson CJ, Middlesworth W, et al. Detection of deletions spanning the Duchenne muscular dystrophy locus using a tightly linked DNA segment. Nature 1985;316:842-5.

23 Thomas NST, Ray PN, Worton RG, Harper PS. Molecular deletion analysis in Duchenne muscular dystrophy. J Med Genet 1986;23:509-15.

${ }^{24}$ Hart K, Cole C, Walker A, et al. The screening of Duchenne muscular dystrophy patients for submicroscopic deletions. $J$ Med Genet 1986;23:516-20.

25 Monaco AP, Kunkel LM. A giant locus for the Duchenne and Becker muscular dystrophy gene. Trends Genet 1987;3:33-7

Correspondence and requests for reprints to Dr K E Davies, Nuffield Department of Clinical Medicine, John Radcliffe Hospital, Headington, Oxford OX3 9DU. 